\title{
Three Mechanisms by which Striatal Denervation Causes Breakdown of Dopamine Signaling
}

\author{
Jakob K. Dreyer \\ Department of Neuroscience and Pharmacology, University of Copenhagen, 2200 Copenhagen, Denmark
}

Progressive loss of nigrostriatal dopamine (DA) neurons is the neuropathological hallmark of Parkinson's disease (PD). Symptoms of the disease can often be treated by $\mathrm{DA} \mathrm{D}_{2}$ agonists and thus seem related to disinhibition of the indirect striatal pathway. However, there is no evidence that symptoms arise by low extracellular DA concentration or are associated with reduced $\mathrm{D}_{2}$ receptor binding. Here I provide a theoretical analysis of the pathophysiology and postsynaptic adaptation resulting from striatal DA denervation. I found that progressive denervation may alter DA signaling by three independent mechanisms depending on degree of denervation and macroscopic morphology of the lesion. As long as the remaining innervation stays anatomically coherent, denervation reduces phasic variations in extracellular DA, but the DA tone is not changed. The reduction of phasic signaling can be partially compensated by upregulating postsynaptic signaling cascades. However, changes in DA dynamics evade compensation. With $80-99 \%$ denervation, a persistent aberrant signal develops in $\mathrm{D}_{2}$-regulated pathways caused by random fluctuations in tonic DA release. Permanent low DA levels occur in regions completely void of innervation. Simulation of $\mathrm{L}$-dopa therapy reduced the aberrant $\mathrm{D}_{2}$ signal. With a high degree of denervation, L-dopa enhanced another aberrant signal, this time in the $\mathrm{D}_{1}$ pathway. This analysis provides a quantitative, physiologically consistent view of the early and late stages of PD, the effect of main therapeutic medications, and potential side effects. The mechanisms described here may also provide an explanation to currently inexplicable pathological phenomena such as psycho stimulant-induced contraversive rotations in animal models.

Key words: supersensitivity; compensation; $\mathrm{D}_{2}$ receptor; dopamine; Parkinson's disease

\section{Introduction}

Parkinson's disease (PD) is a common age-related neurological disease. The classical symptoms include rigidity, bradykinesia, resting tremor, and cognitive symptoms (Lindgren and Dunnett, 2012). The hallmark of PD is progressive degeneration of dopamine (DA) neurons (Hornykiewicz, 2001; Dauer and Przedborski, 2003). Gross motor symptoms may be interpreted as disinhibition of the indirect striatal pathway caused by reduced tonic activation of $\mathrm{D}_{2}$-like receptors (Albin et al., 1989). However, symptoms of PD seem absent until substantial loss has occurred, and in patients with early $\mathrm{PD}, \mathrm{D}_{2}$ receptor binding measured with PET does not correlate with disease duration or severity of symptoms (Brooks et al., 1992; Knudsen et al., 2004). These clinical observations are paralleled in animal studies. Here, on one hand, DA depletion often exceeds $80 \%$ before significant changes in tonic DA levels can be observed (Castañeda et al., 1990). On the other hand, substantial changes in postsynaptic $\mathrm{D}_{1}$

\footnotetext{
Received April 10, 2014; revised July 11, 2014; accepted July 30, 2014

Author contributions: J.K.D. designed research; J.K.D. performed research; J.K.D. contributed unpublished reagents/analytic tools; J.K.D. analyzed data; J.K.D. wrote the paper.

This work was supported by the Lundbeck Foundation. I also thank Jeff A. Beeler (City University of New York, New York, NY) and Mark Humphries (University of Manchester, Manchester, United Kingdom) for commenting on an early version of this work.

The author declares no competing financial interests.

Correspondence should be addressed to Jakob K. Dreyer, Department of Neuroscience and Pharmacology, University of Copenhagen, Blegdamsvej 3, 24.3.45, 2200 Copenhagen, Denmark. E-mail: jakobdr@sund.ku.dk.

DOI:10.1523/JNEUROSCI.1458-14.2014

Copyright $\odot 2014$ the authors $\quad 0270-6474 / 14 / 3412444-13 \$ 15.00 / 0$
}

and $\mathrm{D}_{2}$ receptor signaling cascades require less denervation (Gerfen, 2000; Strömberg et al., 2000; Cai et al., 2002; Gerfen, 2003; Prieto et al., 2009; Sun et al., 2010). Currently, no fully consistent theory can account for progression, symptoms, and medication during all stages of PD. The problem is complicated because the exact delineation between biophysical, physiological, and compensatory changes in the DA signal is unknown.

Here I conduct a theoretical analysis of DA signals in denervated striatum based on a volume transmission model of DA signaling. The model predicts that reduced DA levels occur late in disease when innervation loses spatial coherence. In stages where remaining DA innervation is coherent, the DA tone is maintained, but translation of phasic DA cell firing is reduced. However, when denervation reaches $50 \%$, a mismatch between time scales of DA dynamics and bursts and pauses in firing patterns arises (Grace and Bunney, 1984b). This phenomenon appears with moderate denervation (50-80\%), and affects mainly signaling by high-affinity DA receptors (e.g., high-affinity $\mathrm{D}_{2}$ - and $\mathrm{D}_{3}$ type receptors). I argue below that in animal models with unilateral denervation, this pathology may lead to contraversive rotations in rodents with unilateral lesions when challenged with low doses of DA uptake inhibitors (Robinson et al., 1994; Labandeira-Garcia et al., 1996; Paquette et al., 2009). Denervation above $80 \%$ compromises the signal-to-noise ratio in the DA signal. In combination with adaptive postsynaptic pathways, this leads to a persistent pathological signal, in particular, in pathways regulated by high-affinity receptors. In the model, this persistent 
signal is reduced by L-dopa. The two mechanisms described above appear at stages of denervation where tonic DA levels and tonic receptor occupancy appear normal. However, with sufficient denervation, some areas may end up fully depleted, causing permanent low extracellular DA. DA levels inside voids are increased by L-dopa therapy.

The analysis is compatible with clinical observations such as normal $\mathrm{D}_{2}$ binding in early-stage patients and late onset of symptoms. Furthermore, it accounts for L-dopa therapy including side effects. Finally, the model suggests unexplored features that may aid diagnosis of premotor PD.

\section{Materials and Methods}

Micro-scale model. For partial denervation, the modeling was performed using essentially the same methods used by Dreyer and Hounsgaard (2013). Physiological parameters are mainly determined from rodent studies.

In brief, the micro-scale model simulates DA signals in a cubic $20 \mu \mathrm{m}$ subvolume innervated by an ensemble of DA neurons. In the simulation, DA is calculated at two levels: striatal DA concentration is used to determine postsynaptic effects of DA signals driven by the firing rate of DA neurons; somatodendritic release is used to determine autoreceptor feedback on the DA firing rate.

Striatal DA signaling is modeled from first principles beginning with action potential-dependent vesicular release from distinct release sites. DA signaling is mediated by extracellular volume transmission. When simulating the intact striatum, the micro-volume was filled by 1500 terminals from $N=100 \mathrm{DA}$ neurons, giving a terminal density $\rho=0.1$ terminals $/ \mu \mathrm{m}^{3}$ (Doucet et al., 1986; Dreyer et al., 2010). Reuptake is mediated by DA transporters (DATs) located at release sites (Dreyer and Hounsgaard, 2013). Partial denervation was modeled by reducing $N$, which results in simultaneous reduction of DA release and reuptake (Bergstrom and Garris, 2003). The vesicular release probability was regulated independently for each terminal between 2 and $15 \%$ by autoreceptors sensitive to recent DA concentrations in the neighborhood of the terminal (Dreyer and Hounsgaard, 2013).

The input to the model is the firing rate of DA neurons. Tonic firing was produced by independent Poisson processes of the same constant intensity in each neuron. Phasic signaling was produced by a repeated pattern of high-intensity Poisson firing and pauses (Grace and Bunney, $1984 a, b)$ or a random phasic firing pattern described below. The effective firing rate of DA neurons in the model was determined by the input rate minus a term accounting for somatodendritic autoinhibition (Dreyer and Hounsgaard, 2013). Therefore, the effective firing rate changes when simulating different pharmacological treatments and with denervation. Input firing rates were tuned to produce the effective average firing rate around $4 \mathrm{~Hz}$ in both tonic and phasic firing in simulation of intact and untreated animals.

The core of the micro-scale simulation is a numerical solution to

$$
\begin{aligned}
\frac{\partial C(\mathbf{x}, t)}{\partial t}=\sum_{j=1}^{N} \sum_{\left\{t_{j k}\right\}} \Delta C_{j}(\mathbf{x}, t) \delta\left(t-t_{j k}\right) & +D^{\star} \nabla^{2} C(\mathbf{x}, t) \\
& \\
& -\frac{\sum_{j=1}^{N} V_{\max }^{j}(\mathbf{x}) C(\mathbf{x}, t)}{K_{a p p}+C(\mathbf{x}, t)}-k_{0} C(\mathbf{x}, t) .
\end{aligned}
$$

Here $C(\mathbf{x}, t)$ is concentration of DA at spatial coordinate $\mathbf{x}=(x, y, z)$ and at time $t$ in a small representative volume of striatum. The first term on the right expresses spike-driven DA release. Here release is summed over $j=$ $1, \ldots, N$ neurons. The set of spike arrival times for each neuron, $\left\{t_{\mathrm{jk}}\right\}$, is determined by an independent Poisson process with common intensity for all neurons given by the firing rate $v(t)$. At time points where neuron $j$ has a spike, the dopamine concentration is raised by $\Delta C_{j}(\mathbf{x}, t)$, the spatiotemporal vesicular release pattern for each neuron. The release pattern incorporates the location of fixed release sites (hence, the dependence on $\mathbf{x})$ and terminal autoreceptor feedback of release probability at each release site (hence, the dependence on $t$ ). The second term in Equation 1 represents diffusion in the extracellular space. The diffusion constant, $D^{*}=322 \mu \mathrm{m}^{2} / \mathrm{s}$, includes a correction for tortuosity of extracellular space (Syková and Nicholson, 2008). The third term represents DATmediated uptake. Here uptake is shown explicitly as a sum of contributions of different neurons, with $V_{\max }^{j}(\mathbf{x})$ representing a spatial pattern of DAT expression that coincides with the release sites of neuron $j$. Thus, DAT-mediated uptake is present at release sites only (hence, dependence on $\mathbf{x}) . K_{\text {app }}$ is the apparent Michaelis-Menten constant. In drug-free conditions, $K_{\text {app }}$ is equal to the Michaelis-Menten constant $K_{m}=0.16$ $\mu \mathrm{M}$. When simulating competitive DAT inhibition, $K_{\text {app }}$ is set higher than $K_{\mathrm{m}}$. Details of the autoreceptor feedback, spatial-dependent $V_{\max }$ and relationship between $K_{\text {app }}$ and DAT inhibition is given by Dreyer and Hounsgaard (2013) and references therein. The fourth term is a firstorder process representing enzymatic degradation and nonspecific uptake of DA, which is further discussed below. Simulations were performed on a $24 \times 24 \times 24 \mu \mathrm{m}$ spatial grid with $0.6 \mu \mathrm{m}$ resolution and with a 0.16 ms time step.

In this study, the most important control parameter is the number of neurons, $N$, which appears as the top limit in the summations of Equation 1. In normal conditions, $N=100$ (Dreyer et al., 2010) and lower when simulating a denervated area. The value of $N$ has influence on the number of release sites in the simulation volume and, therefore, also affects uptake. Note that the micro-scale model is only valid if at least one neuron remains in the simulation volume.

The difference between the micro-scale model used here and in previous work (Dreyer and Hounsgaard, 2013) is a first-order process reflecting nonspecific uptake by norepinephrine transporters and enzymatic degradation, for example, by monoamine oxidase B (MAO-B). Above, the combined effect of these factors is implemented as a spatially independent first-order decay (in striatum, $k_{0}=0.04 \mathrm{~s}^{-1}$; Budygin et al., 2002). A similar first-order process, $k_{0}^{\text {soma }}=0.007 \mathrm{~s}^{-1}$ (Cragg et al., 2001), was introduced in the calculation of somatodendritic DA used to determine feedback by somatodendritic autoreceptors (Dreyer and Hounsgaard, 2013). In the intact condition, reduction of DA levels by nonspecific DA removal is vanishing in both dorsal striatum (DS) and somatodendritic areas. However, since $k_{0}$ is independent of DA innervations, this term will play an increasing role with progressive denervation and has been hypothesized to be the cause of low DA levels at high denervation (Reed et al., 2009). Because of the slightly lower ratio between $k_{0}^{\text {soma }}$ and $V_{\max }^{\text {soma }}$, the effect of the first-order decay becomes first apparent in somatodendritic areas and later in striatal areas. However, as shown in the present study, nonspecific uptake does not lead to aberrant signaling for any value of $N \geq 1$.

Generation of double-stochastic firing patterns. A random phasic firing pattern was generated using a mother train of spikes with interspike intervals after a gamma distribution (coefficient of variation $=1.0 ; \nu=5$ $\mathrm{Hz}$ ). The spike arrival times of the mother train were binned at the time resolution of the simulation. The histogram was then smoothed using a Gaussian kernel with half-width $100 \mathrm{~ms}$. This produced a smooth random time-varying firing rate $\nu(t)$ with bursts up to $20 \mathrm{~Hz}$ and pauses up to $1 \mathrm{~s}$.

The resulting firing rate $\nu(t)$ was subjected to somatodendritic feedback and used as intensity in the Poisson process generating $\left\{t_{\mathrm{jk}}\right\}$, the spike input to the model. In the intact case, the average effective firing rate was $4.3 \mathrm{~Hz}$; on average, neurons had $47 \%$ spikes in bursts according to the 80-160 ms criterion (Grace and Bunney, 1984b), and the coefficient of variation of the interspike intervals was $120 \%$.

Simulation of DA uptake inhibition. Investigations of the effect of DA uptake inhibition was performed using the same methods as described by Dreyer and Hounsgaard (2013). In short, competitive uptake inhibition was modeled by increasing $K_{\text {app }}$, the apparent Michaelis-Menten uptake constant in both terminal and somatodendritic regions. The value of $K_{\text {app }}$ was interpreted as an equivalent dose of intraperitoneal cocaine administered $20 \mathrm{~min}$ earlier. For example, $K_{\text {app }}=0.160 \mu \mathrm{M}$ corresponds to $0 \mathrm{mg} / \mathrm{kg}$ cocaine and $K_{\mathrm{app}}=1.0 \mu \mathrm{M}$ to $15 \mathrm{mg} / \mathrm{kg}$, i.p. cocaine.

Continuum model for DA release with voids. Since the size of fully depleted striatal areas may be on the order of $1 \mathrm{~mm}$, similar to the macroscopic size of DA arbors (Matsuda et al., 2009), the micro-scale model is not suitable. Therefore, calculation of tonic DA levels in the presence of 
A

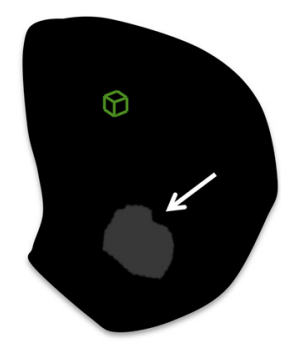

B

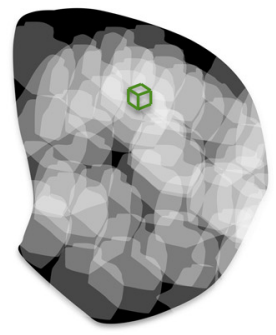

E

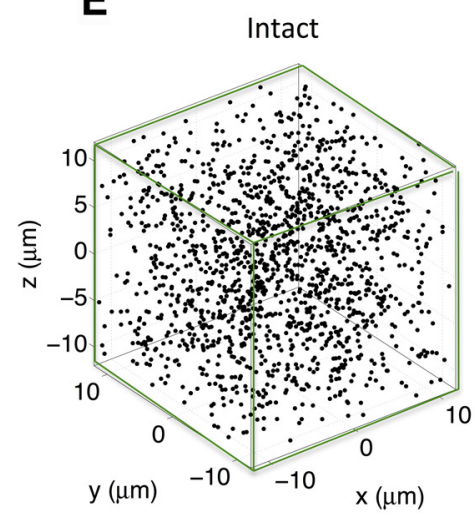

C

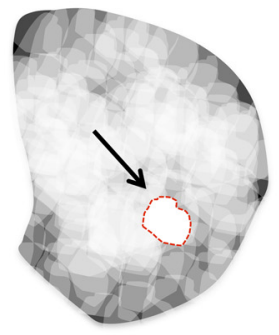

F

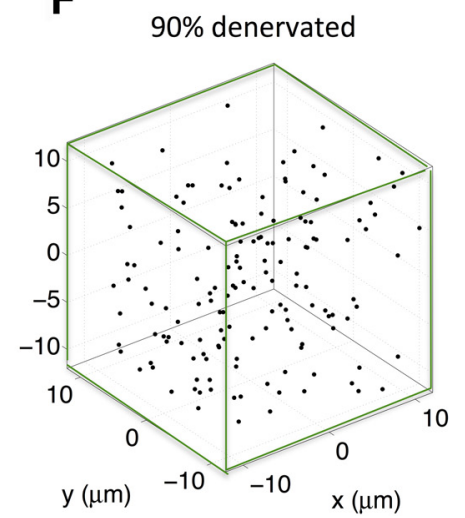

D

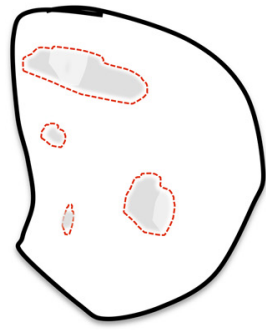

Intact

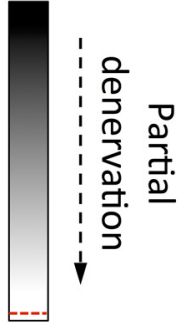

Depleted

G

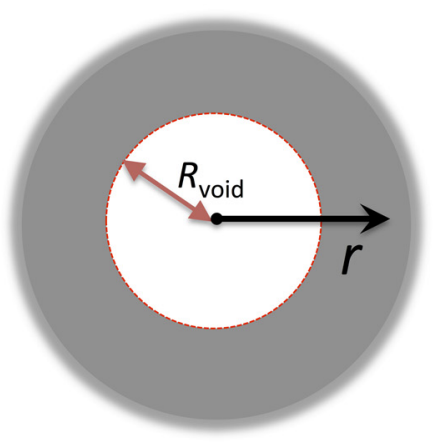

Figure 1. Schematic view of denervation processes in rodent striatum and summary of idealized biophysical models. $\boldsymbol{A}-\boldsymbol{D}$, Gradual denervation leads to a complex innervation landscape. Gray scale, Denervation; black, intact; white, completely denervated. Red dashed lines show the boundary for fully depleted areas. $A$, A single neuron is lost (gray scale exaggerated for illustration). The miniature green cube illustrates the simulation volume of $\boldsymbol{E}$ (not to scale). $\boldsymbol{B}$, Multiple neurons are lost, but voids are absent. The miniature green cube illustrates the simulation volume of $\boldsymbol{F}$ (not to scale). $\boldsymbol{C}$, Void nucleated at critical neuron loss (arrow). D, Late-stage PD: few neurons left, voids dominate. $\boldsymbol{E}$, Micrometer-scale simulation volume for intact striatum. $\boldsymbol{F}$, Ninety percent depleted (simulation volumes around $20 \mu \mathrm{m}$ diameter). $G$, Continuum model of DA void; the typical void radius is from 100 to $500 \mu \mathrm{m}$.

voids uses a continuum model based on the same physiological parameters as the micro-scale model. In the continuum model, vesicular release from single distinct terminals is replaced by spatial average controlled by a terminal density parameter, $\rho$, and discrete action potentials were replaced by a constant firing rate, $\nu_{0}$. Also, the continuum model does not include autoreceptors explicitly. Rather, the firing rate and release probability were determined using the micro-scale model described above.

A DA void was modeled as a spherical region of radius $R_{\text {void }}$ (Fig. $1 G$ ). The terminal density was 0 inside the void and $\rho_{0}$ outside. In other words, the terminal density is defined as follows:

$$
\rho(r)= \begin{cases}0 & \text { for } r \leq R_{\text {void }} \\ \rho_{0} & \text { for } r>R_{\text {void }}\end{cases}
$$

In the present study, I used $\rho_{0}=0.1$ terminals $/ \mu \mathrm{m}^{3}$ as terminal density for intact striatum (Doucet et al., 1986) and a $90 \%$ denervation thereof $\left(\rho_{0}=0.01\right.$ terminals $\left./ \mu \mathrm{m}^{3}\right)$.

With these assumptions, the DA concentration, $C$, can be fully described as a function of distance from the void center, $r$, and time $t$. Expressed in spherical coordinates, the modeled equation for DA levels becomes the following:

$$
\begin{aligned}
\frac{\partial C(r, t)}{\partial t}=I_{\mathrm{DA}}(r)+D^{*}\left[\frac{\partial^{2} C(r, t)}{\partial r^{2}}+\frac{2}{r} \frac{\delta C(r, t)}{\delta r}\right] \\
\\
-\frac{V_{\max }(r) C(r, t)}{K_{M}+C(r, t)}-k_{0} C(r, t) .
\end{aligned}
$$

The first term in Equation 3 describes DA release and is given by the following:

$$
I_{\mathrm{DA}}(r)=\rho(r) \frac{P_{r} n_{0}}{\alpha N_{A}} \nu_{0}
$$

where $P_{\mathrm{r}}$ is the vesicular release probability, $n_{0}$ is the number of molecules released per vesicle fusion $\left[n_{0}=3000\right.$ and 9000 in simulation of L-dopa therapy (Pothos et al., 1998)], $\alpha$ is the extracellular volume fraction (Syková and Nicholson, 2008), $N_{A}$ is the Avogadros constant, and $\nu_{0}$ is the average firing rate of DA neurons. I used $\nu_{0}=4 \mathrm{~Hz}$ and $\nu_{0}=3 \mathrm{~Hz}$ when simulating L-dopa therapy. Under L-dopa administration, DA corelease from serotonergic neurons might also contribute to the DA level inside the void. The magnitude of this contribution is estimated below using a modified version of Equation 3 .

The second term of Equation 3 describes diffusion of DA in the extracellular space. The diffusion coefficient, $D^{*}$, includes the effect of tortuosity (Syková and Nicholson, 2008). The third and fourth terms describe removal of DA from extracellular space. Here,

$$
V_{\max }(r)=\rho(r) V_{\max }^{\text {term }}
$$

and describes DAT-mediated removal. Note that DAT uptake is scaled with the terminal density $\rho(r)$ and is, therefore, 0 inside the void. Outside the void, it is controlled by $V_{\max }^{\mathrm{term}}=40\left(\mu \mathrm{M} \mu \mathrm{m}^{3}\right) / \mathrm{s}$, indicating the amount of reuptake normalized by terminal density in units of $\mu \mathrm{m}^{-3}$ ( $V_{\max }^{\text {term }}$ plays a similar role as $V_{\max }^{j}(\mathbf{X})$ in Eq. 1 ).

Equation 3 was solved numerically using the forward Euler method. The radial axis represented physical space from 0 to $r_{\max }=1000 \mu \mathrm{m}$ with $2 \mu \mathrm{m}$ increments. The boundary conditions were $\left.\frac{\delta C}{\delta r}\right|_{r=0}=\left.\frac{\delta C}{\delta r}\right|_{r=r_{\max }}=0$. The time increment in the simulation corresponded to $5 \mathrm{~ms}$.

Estimation of DA corelease from striatal serotonergic terminals. A version of the continuum model described above was also used to estimate the impact of DA corelease from serotonergic neurons (Carta et al., 2008). Here, space dependencies are ignored. Equation 3 can then be modified to the following: 


$$
\frac{d C(t)}{d t}=I_{\mathrm{DA}}^{\mathrm{DAN}}+I_{\mathrm{DA}}^{\mathrm{HT}}-\frac{V_{\max } C(t)}{K_{\mathrm{app}}+C(t)}-k_{0} C(t) .
$$

Here $I_{\mathrm{DA}}^{\mathrm{DAN}}$ represents DA release from DA terminals and is determined using Equation 4 with parameters and the firing rate relevant for L-dopa therapy as described above. The second term, $I_{\mathrm{DA}}^{\mathrm{HT}}$, represents DA release from serotonergic terminals. This term was estimated using $\rho=0.0026$ $\mu \mathrm{m}^{-3}$ (Soghomonian et al., 1987) and firing rate $v_{0}=1 \mathrm{~Hz}$ (Aghajanian et al., 1978). The release probability was assumed to be $10 \%$, and the number of DA molecules per vesicle was assumed to $300,10 \%$ of vesicular contents for DA neurons (Pothos et al., 1998). $V_{\max }$ was determined using Equation 5 and scaled with DA innervation. Solving Equation 6 for steady state yields a quadratic polynomial in $C$, the solution to which gives the steady-state DA level as follows:

$$
C_{0}=\frac{-B+\sqrt{4 k_{0} K_{M}\left(I_{\mathrm{DA}}^{5 \mathrm{HT}}+\mathrm{I}_{\mathrm{DA}}^{5 \mathrm{HT}}\right)-B^{2}}}{2 k_{0}},
$$

where:

$$
B=V_{\max }+K_{M} \mathrm{k}_{0}-\mathrm{I}_{\mathrm{DA}}^{5 \mathrm{HT}}-\mathrm{I}_{\mathrm{DA}}^{5 \mathrm{HT}} .
$$

Note that in Equation 6, both $V_{\max }$ and $I_{\mathrm{DA}}^{\mathrm{DAN}}$ are affected by denervation, whereas $I_{\mathrm{DA}}^{5 \mathrm{HT}}$ is not.

\section{Estimation of rate of second-messenger production in postsynaptic medium spiny neurons}

Experimental studies have shown that in striatal medium spiny neurons (MSNs), the number of DA receptors, their G-proteins, and expression of adenylyl cyclase (AC) is affected by denervation (Strömberg et al., 2000; Cai et al., 2002; Gerfen, 2003; Prieto et al., 2009; Sun et al., 2010). Here my aim is to develop a generic scheme relating the number of functional $\mathrm{D}_{1}$ and $\mathrm{D}_{2}$ signaling units, $N_{\mathrm{D} 1}$ and $N_{\mathrm{D} 2}$, to the production of second messenger ( $\mathrm{SM}$ ) molecules such as cAMP in postsynaptic direct and indirect MSNs. Here a postsynaptic signaling unit is defined as the whole chain leading to production of SM molecules, e.g., a $D_{1}$-regulated signaling unit may comprise $\mathrm{D}_{1}$ receptor, $\mathrm{G}$-protein, and substrate. The number of activated $D_{1}$ signaling units at time $t$ is given by the product of $N_{\mathrm{D} 1}$ and D1 $(t)$, where $\mathrm{D} 1(t)$ is the activated fraction of $\mathrm{D}_{1}$ receptors.

I assumed that the rate of $\mathrm{D}_{1}$-regulated $\mathrm{SM}$ production is proportional to the number of activated low-affinity $\mathrm{D}_{1}$-like receptor units $\left[\mathrm{EC}_{50}=1\right.$ $\mu \mathrm{M}$ (May, 1992)],

$$
\Delta \mathrm{SM}_{\mathrm{D} 1}(t)=N_{\mathrm{D} 1}\left(\mathrm{D} 1(t)-\langle\mathrm{D} 1\rangle_{\text {tonic }}\right) \cdot \Theta\left(\mathrm{D} 1(t)-\langle\mathrm{D} 1\rangle_{\text {tonic }}\right) .
$$

Here $\Delta \mathrm{SM}_{\mathrm{D} 1}(t)$ is the rate of $\mathrm{D}_{1}$-activated SM production at time $t$. The net SM production is balanced by the mean receptor activation of tonic firing, $\langle\mathrm{D} 1\rangle_{\text {tonic }}$, and is kept positive by the step function $\Theta(x)(\Theta(x)=0$ when $x<0$ and $\Theta(x)=1$ when $x \geq 0)$. Note that, by definition of the signaling unit, increasing $N_{\mathrm{D} 1}$ implicitly implies that the substrate is upregulated concurrently (Rangel-Barajas et al., 2011).

Activation of high-affinity $\mathrm{D}_{2}$-like receptors is assumed to inhibit second-messenger production $\left[\mathrm{EC}_{50}=10 \mathrm{nM}(\right.$ May, 1992)]. The rate of $\mathrm{D}_{2}$-related SM production, $\Delta \mathrm{SM}_{\mathrm{D} 2}$, is assumed to be proportional to the number of disinhibited signaling units, which may be expressed as follows:

$$
\Delta \mathrm{SM}_{\mathrm{D} 2}(t)=\mathrm{N}_{\mathrm{D} 2}\left(\langle\mathrm{D} 2\rangle_{\text {tonic }}-\mathrm{D} 2(t)\right) \cdot \Theta\left(\langle\mathrm{D} 2\rangle_{\text {tonic }}-\mathrm{D} 2(t)\right) .
$$

As in Equation 9, increasing the constant of proportionality, $N_{\mathrm{D} 2}$, implicitly assumes that the number of inhibited substrates is also increased. The absolute number of signaling units, $N_{\mathrm{Dx}}(x=1,2)$, is not of interest here. They are set to 1 for intact striatum, and only relative changes therein are reported. The postsynaptic signal described here is only one of many possible schemes that meets two fundamental requirements: SM production is reduced by tonic DA firing, and the sensitivity to phasic signals can be regulated via the number of signaling units.

As a general rule, I assume that the rate of SM production provides negative feedback to $N_{\mathrm{Dx}}$, thereby controlling the sensitivity of the sig- naling cascade (Barton and Sibley, 1990). This feedback was implemented as follows:

$$
N_{\mathrm{D} 1}=\frac{\left\langle\left(\mathrm{D} 1(t)-\langle\mathrm{D} 1\rangle_{\text {tonic }}\right) \cdot \Theta\left(\mathrm{D} 1(t)-\langle\mathrm{D} 1\rangle_{\text {tonic }}\right)\right\rangle_{\text {intact }}}{\left\langle\left(\mathrm{D} 1(t)-\langle\mathrm{D} 1\rangle_{\text {tonic }}\right) \cdot \Theta\left(\mathrm{D} 1(t)-\langle\mathrm{D} 1\rangle_{\text {tonic }}\right)\right\rangle_{\text {denerv }}}
$$

and likewise for $N_{\mathrm{D} 2}$. In Equation 11, $\left\langle\left(\mathrm{D} 1(t)-\langle\mathrm{D} 1\rangle_{\text {tonic }}\right) \cdot \Theta\right.$ $\left.\left(\mathrm{D} 1(t)-\langle\mathrm{D} 1\rangle_{\text {tonic }}\right)\right\rangle_{\text {intact }}$ is the mean $\mathrm{D}_{1}$ signal in intact striatum, and $\left\langle\left(\mathrm{D} 1(t)-\langle\mathrm{D} 1\rangle_{\text {tonic }}\right) \cdot \Theta\left(\mathrm{D} 1(t)-\langle\mathrm{D} 1\rangle_{\text {tonic }}\right)\right\rangle_{\text {denerv }}$ is for denervated conditions. Consequently, a long-term reduction of phasic DA signaling will lead to an increased number of signaling units and, hence, increased sensitivity of the regulatory pathway; increased phasic signaling will reduce sensitivity of signaling pathways. I calculated $N_{\mathrm{D} x}$ using a $120 \mathrm{~s}$ double-stochastic phasic firing pattern.

Inhibition of adenylate cyclase may be taken as an example of the $\mathrm{D}_{2}$-like receptor action modeled by Equations 10 and 11 . However, this is only one of several known actions of postsynaptic $\mathrm{D}_{2}$-like receptors (Bonci and Hopf, 2005; Beaulieu and Gainetdinov, 2011). However, the results derived here do not depend on precise workings of the receptor and are fully generalizable. The only control parameter used here is the $\mathrm{EC}_{50}$ of activation/inhibition.

\section{Results}

Here I will analyze the degree to which DA neurons can transmit signals to their postsynaptic targets at different degrees of denervation. I will focus on how denervation affects activation of lowaffinity $\mathrm{D}_{1}$-like receptors $\left(\mathrm{EC}_{50}=1000 \mathrm{nM}\right)$ and high-affinity members of the $\mathrm{D}_{2}$-like family $\left[\mathrm{EC}_{50}=10 \mathrm{nM}(\mathrm{May}, 1992)\right] . \mathrm{D}_{2}$ and $\mathrm{D}_{3}$ receptors are targets of medication and, therefore, of particular interest for PD (Hobson et al., 1999). For simplicity of the present analysis, both are denoted as $\mathrm{D}_{2}$ and are assumed to have a similar affinity for DA.

\section{Anatomy of DA denervation may lead to distinct pathologies} DA denervation causes multiple and complex changes in striatum. My efforts to capture a wide range of denervation patterns require different computational methods for modeling the different pathologies that may arise. To substantiate and qualify the discussion below, I first start by a qualitative analysis of DA innervation at different stages of denervation.

Nigrostriatal DA neurons form widely branched axonal arbors in striatum. In rats, a single neuronal arbor may cover $0.5-5 \%$ of the total striatal volume, and neurons overlap considerably so that a single postsynaptic neuron may receive signals from 100 to 200 presynaptic DA neurons (Matsuda et al., 2009). Therefore, loss of a single DA neuron merely reduces the innervation density in a particular subvolume (Fig. $1 A$ ). As increasingly more DA neurons are lost, more areas become affected causing a heterogeneous spatial innervation pattern (Fig. 1B). At early stages of the denervation process, the innervation remains coherent, as it is unlikely that some area will end up completely without DA innervation. However, the probability that fully depleted areas appear increases with every neuron lost. Eventually, voids in DA innervation may occur (Fig. 1C). If the degeneration of neurons is random, the appearance of voids will be variable in time and space. Nonrandom mechanisms may cause voids to form more readily in particular anatomical areas (Kish et al., 1988). Once voids are nucleated, however, further neuronal loss may increase the number or volume of voids until only isolated innervated areas remain (Fig. 1D). The progression described here may be compared with the quantification of postmortem DAT immunoreactivity in putamen recently described by Kordower et al. (2013).

The analysis above indicates that different types of signals may be expected depending on the topology of remaining innerva- 
tion. I will start by quantifying DA signals with in coherent partial denervation. Signaling in this regime is investigated using a computational model that addresses striatal DA signaling at the micro-scale, and denervation is modeled by varying the density of DA release sites (Fig. $1 E, F$ ). The micro-scale model may approximate the case of homogeneous denervation assuming that a large area is consisting of identical micro-volumes.

Then, I will ask how DA signals in homogeneous denervation lead to adaptation of postsynaptic signaling cascades, and, in particular, whether there are aspects of the DA signal in the denervated state that evades compensation.

I will then investigate tonic DA levels around a fully depleted void using a macro-scale model. This model represents a spatial and temporal continuum representation of the micro-scale model (Fig. 1G).

\section{Constant DA tone but reduced phasic DA signals in partial} homogeneous denervation

Experimental studies with partial denervation show that tonic DA levels are unchanged (Castañeda et al., 1990), but phasic signaling, evoked or spontaneous, has reduced amplitude (Sandberg and Phillips, 2009; Howard et al., 2011, 2013). Bergstrom and Garris (2003) noted that constant DA levels may be a consequence of concurrent loss of release and uptake; an effect termed "passive stabilization." However, previous theoretical considerations assume ideal "well-mixed" extracellular compartments and speculate that nonspecific uptake eventually reduces DA levels at sufficient denervation (Bergstrom and Garris, 2003; Reed et al., 2009). The 3D volume transmission model accounts for terminal release and uptake explicitly and is, therefore, well suited for testing this assumption. Consequently, I characterized tonic and phasic DA signals and asked whether the model reproduces experimental data and whether low DA levels occur with high denervation.

When the number of DA neurons is reduced, there is a change in fundamental physiological parameters of the striatum and substantia nigra. In particular, the density of DA terminals, the sites for DA release and uptake, has primary influence on the lifetime of striatal extracellular DA. The biophysical model used here allows us to investigate how this change in the physiological makeup affects the translation of DA neuronal firing to activation postsynaptic target receptors. As a test pattern, I applied $4 \mathrm{~Hz}$, nonsynchronized tonic firing, which shifts to a burst firing pattern consisting of brief episodes of $20 \mathrm{~Hz}$ firing (on average, four spikes) followed by a $0.8 \mathrm{~s}$ pause (Fig. $2 \mathrm{~A}$; spikes of 15 neurons are indicated as dots, transition from tonic to phasic occurs at $t=6 \mathrm{~s}$ ). The combination of these firing patterns represents typical firing behavior of DA neurons (Grace and Bunney, 1984a, b).
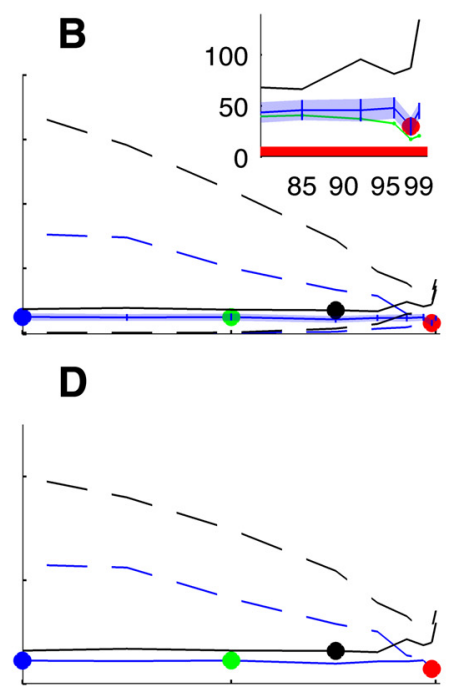

$\mathbf{F}$

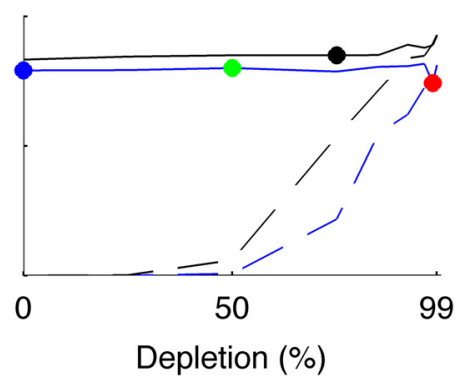

Time (s)

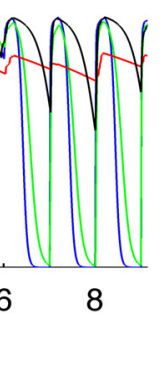

Figure 2. Effect of partial denervation on tonic and phasic DA signaling. $A, C, E$, Example time series of DA signals from tonic and phasic firing with different innervation density. Blue, Intact; green, $50 \%$ denervated; red, $98 \%$ denervated; black, $75 \%$ denervated of low-affinity $D_{1}$ receptors (only top dashed line shown). $\boldsymbol{E}$, Tonic and phasic activation of $D_{2}$ receptors. $\boldsymbol{F}$, Summary of high-affinity $D_{2}$ receptors (only bottom dashed line shown). Colored symbols in $\boldsymbol{B}, \boldsymbol{D}$, and $\boldsymbol{F}$ indicate conditions shown in $\boldsymbol{A}, \boldsymbol{C}$, and $\boldsymbol{E}$.

I first investigated the effect of denervation on DA levels from tonic activity of DA neurons (Fig. 2A,C,E; blue, intact; green, $50 \%$ denervated; red, $98 \%$ denervated). As in previous simulation studies (Dreyer et al., 2010; Dreyer and Hounsgaard, 2013), tonic firing of DA neurons resulted in striatal extracellular DA concentrations around $50 \mathrm{~nm}$. Random fluctuations in firing rate and vesicular release lead to a typical SD of $10 \mathrm{~nm}$. However, with denervation, the mean and $\mathrm{SD}$ of the DA concentration remained approximately the same (Fig. $2 A$, compare blue, green, and red; see also Fig. $2 B$, solid blue line). Different competing mechanisms provided slight influence on tonic DA levels at high denervation. On one hand, denervation lead to slightly lower inhibitory feedback on the firing rate, which tended to increase DA levels. On the other hand, fewer vesicular release events lead to less saturation of terminal DATs. This effect led to a slightly lower DA level. However, these mechanisms provided only subtle perturbations of little functional relevance. Even in the extreme case with terminal density representing a single DA axon (99\% denervation), DA levels were $44 \mathrm{nM}$, well within the random fluctuations of DA levels in the intact striatum (Fig. $2 B$, inset, blue). Even when nonspecific uptake was increased to $0.4 \mathrm{~s}^{-1}, 10$ times the experimental value (Budygin et al., 2002), 99\% denervation gave a DA 
level of $20 \mathrm{nM}$, well above the $\mathrm{EC}_{50}$ of high-affinity receptors (Fig. $2 B$, inset, green; the red bar shows the $10 \mathrm{~nm}$ level). Thus, according to the present model of DA signaling, tonic DA is virtually unchanged in areas with any remaining innervation. In these areas, uptake via the remaining DATs is the dominant source of removal of DA compared with other sources.

In the model, the tonic firing led to constant activation of postsynaptic receptors. $\mathrm{D}_{1}$ had activation between 4 and $6 \%$ (Fig. $2 \mathrm{C}, t<6 \mathrm{~s}, D$, solid blue line), and $\mathrm{D}_{2}$ had activation around $80 \%$ (Fig. 2E, $t<6 \mathrm{~s}, F$, solid blue line). This baseline activation of receptors did not change even up to $99 \%$ denervation.

Bursts and pauses of phasic DA firing patterns provide a temporal signal (Grace and Bunney, 1984b; Schultz, 1998). The computational model used here predicts that in the intact striatum, phasic signals are efficiently decoded by postsynaptic receptors, where $D_{1}$ receptors are particularly sensitive to high DA levels from bursts and $\mathrm{D}_{2}$ receptors are sensitive to low DA levels during pauses (Dreyer et al., 2010; Dreyer and Hounsgaard, 2013; and see also experimental study by Porter-Stransky et al., 2013).

In the intact striatum, DA levels fluctuated in the range from 0 to $300 \mathrm{~nm}$ during phasic firing (Fig. $2 A, t>6 \mathrm{~s}$, blue). As innervation was reduced, the amplitude of the phasic DA signal declined (Fig. $2 A, t>6 \mathrm{~s}$, compare blue, green, and red; Fig. $2 B$, blue dashed lines show minimum and maximum of phasic DA as a function of denervation). The decline of the phasic peaks and troughs in DA concentration affected both $\mathrm{D}_{1}$ and $\mathrm{D}_{2}$ receptor activation (Fig. 2C,D, green and red, E, F, dashed blue). Highaffinity receptors were increasingly locked in a saturated state, whereas low-affinity receptors remained steadily activated at a low level.

Thus, the micro-scale model used here reproduces the passive stabilization of DA levels observed experimentally. However, no reduction of DA tone occurs even with terminal densities as low as $1 \%$ of the intact. The ability of bursts or pauses to affect the DA signal depends on factors that are proportional to the density of terminals ( $V_{\max }$ and DA release). Thus, in the present model, the phasic signal declines linearly with the number of remaining DA neurons innervating the area.

On the other hand, the variability of tonic DA depends on opposing factors that nearly cancel: encoding the signal in fewer neurons increases noise, but the longer lifetime of released DA acts like a low-pass filter reducing the variability of the DA level. Thus; noise approximately remains constant (Fig. 2B, blue shade shows SD from $30 \mathrm{~s}$ tonic firing). The overall result is a reduced signal-to-noise ratio between tonic and phasic signals when innervation is low. In other words, denervation weakens the functional difference between tonic levels and phasic signaling and reduces the amplitude of dynamical responses of postsynaptic receptors.

\section{Supersensitive postsynaptic signaling partially compensates loss of phasic DA signals}

A number of studies show that the expression of postsynaptic $D_{1}$ and $\mathrm{D}_{2}$ receptors, their $\mathrm{G}$-proteins, and intracellular partners such as AC are affected by denervation (Cai et al., 2002; Gerfen, 2003; Sun et al., 2010; Rangel-Barajas et al., 2011). Increased sensitivity of DA receptors occurs at early stages of denervation (Labandeira-Garcia et al., 1996; Gerfen, 2000) where no reduction in DA seems to occur (Castañeda et al., 1990). In light of the results above, an immediate question is whether supersensitivity results from loss of phasic signaling. I therefore asked to which degree varying the sensitivity of postsynaptic signals would compensate loss of phasic DA signaling in partial denervation. Acti- vation or inhibition of adenylyl cyclase $(\mathrm{AC})$ by $\mathrm{D}_{1}$-like and $\mathrm{D}_{2}$ like receptors may be considered an example of this. However, the adaptation is described as a general process and may also apply to other pathways regulated by these receptors (Bonci and Hopf, 2005; Beaulieu and Gainetdinov, 2011).

$\mathrm{D}_{1}$-regulated production of SM molecules was assumed to be activated by $\mathrm{D}_{1}$ binding and proportional to $N_{\mathrm{D} 1}$, the total number of $\mathrm{D}_{1}$ receptor signaling units (Eq. 9; a signaling unit comprising the receptor, G-protein, and substrate, such as AC). The rate of $\mathrm{D}_{2}$-regulated $\mathrm{SM}$ production was inhibited by activation of $\mathrm{D}_{2}$ receptors and the rate proportional to $N_{\mathrm{D} 2}$, the total number of $\mathrm{D}_{2}$ signaling units (Eq. 10). In both cascades, SM production was balanced by the occupancy at tonic firing, and the production was taken to be only positive. With this assumption, the $D_{1}$ receptor-regulated cascades responded when DA was higher than tonic, and $\mathrm{D}_{2}$ cascades responded when DA was lower than tonic. In principle, SM production is 0 in both pathways when subjected to tonic firing. However, since the stochastic elements of the model produce random fluctuations in tonic DA levels, a residual production of second messengers from tonic firing is expected.

I used a double stochastic phasic firing pattern as input to the model and investigated the effect of denervation on the number of signaling units. Again, the average DA level was not affected by denervation, but the phasic response diminished. At very high denervation, the functional difference between tonic and phasic DA cell firing was almost gone (Fig. 3A; tonic firing, $t<120 \mathrm{~s}$; phasic firing, $t>120 \mathrm{~s}$; three examples shown at 0,75 , and $97 \%$ denervation). In the intact striatum, the production of SMs in postsynaptic $\mathrm{D}_{1}$ - and $\mathrm{D}_{2}$-regulated pathways was low with tonic cell firing and high with phasic signaling. Thus, the cumulative production rose slowly under tonic firing but fast under phasic firing. In the absence of adaptation, the rate of production would decline with increasing denervation (Fig. $3 B$, cumulative SM production in arbitrary units; tonic firing, $t<120 \mathrm{~s}$; phasic firing, $t>$ 120 s; blue, intact; green 75\% denervated; red, 97\% denervation).

However, postsynaptic signaling cascades may adapt to reduced postsynaptic activity. A biologically plausible scheme is to let the rate of SM production provide negative feedback on the signaling cascade (Barton and Sibley, 1990). Thus, elevated DA signaling production will attenuate the pathway, and reduced DA signals will slowly upregulate pathways. To implement this, I regulated the number of $\mathrm{D}_{1}$ and $\mathrm{D}_{2}$ signaling units, $N_{\mathrm{D} 1}$ and $N_{\mathrm{D} 2}$, inversely proportional to the phasic DA signals acting on $\mathrm{D}_{1}$ and $\mathrm{D}_{2}$ receptors (Eq. 11).

This scheme led to low $\mathrm{D}_{1}$ adaptation at moderate denervation (e.g., $N_{\mathrm{D} 1}$ increased by $27 \%$ with $75 \%$ denervation, Fig. $3 D$, blue), but increasing at high denervation $\left(N_{\mathrm{D} 1}\right.$ increased $85 \%$ with $94 \%$ denervation, Fig. $3 D$, blue). For $\mathrm{D}_{2}$ receptors, the predicted adaptation was qualitatively similar, but the absolute magnitude was higher (e.g., $N_{\mathrm{D} 2}$ increased by $100 \%$ with $75 \%$ denervation and by $400 \%$ at $92 \%$ denervation, Fig. $3 E$, blue). With high denervation, however, large variation occurred in $\Delta \mathrm{SM}_{\mathrm{D} 1}$ and $\Delta \mathrm{SM}_{\mathrm{D} 2}$ as these were increasingly dominated by few large episodes and long periods of no activity (Fig. $3 D$, E, blue shades indicate SE of $N_{\mathrm{D} 1}$ and $N_{\mathrm{D} 2}$ from $N=4$ simulations).

\section{Supersensitive postsynaptic signaling leads to aberrant signals}

With $75 \%$ denervation, the resulting $\mathrm{D}_{1}$-regulated postsynaptic signal was qualitatively similar to the intact (Fig. 4A, compare top and middle traces). For $\mathrm{D}_{2}$ receptors, the postsynaptic response to small pauses was undercompensated, whereas the response for 
large signals was overcompensated (Fig. $4 B$, middle trace has jagged amplitude for $t>120$ s compared with top trace). With $97 \%$ denervation, the postsynaptic signals missed many small phasic events (Fig. $4 A, B$, compare top and bottom traces for $t>120 \mathrm{~s})$.

However, the most striking effect of denervation occurred in the residual $\Delta \mathrm{SM}$ under tonic firing patterns (Fig. $4 A, B ; t<$ $120 \mathrm{~s}$ ). Normally, the tonic firing pattern leads to low production of second messengers. For example, the predicted residual production of $\mathrm{D}_{1}$-regulated pathways was $28 \%$ of the production under the phasic firing pattern, and the $\mathrm{D}_{2}$-regulated production was $13 \%$ of the production with phasic firing (Fig. $4 A, B$, top trace; compare $t<120 \mathrm{~s}$ with $t>120 \mathrm{~s}$ ). However, the adaptive response to reduced phasic signaling also increased the residual production by tonic firing. With high denervation, a persistent aberrant signal occurred (Fig. 4A, B, compare bottom and top traces for $t<120 \mathrm{~s}$ ). For $\mathrm{D}_{1}$ receptors, the aberrant signal was around a factor of 2 at $92 \%$ denervation and above (Fig. 4, blue). At high denervation, the aberrant $D_{1}$ signal reached $\sim 50 \%$ of the phasic $\mathrm{D}_{1}$ signal (Fig. $4 E, F$, black dashed lines indicate $\Delta \mathrm{SM}_{\mathrm{D} 1}$ for the phasic firing pattern and intact striatum). The increase was most prominent for the $\mathrm{D}_{2}$ cascade, with a twofold increase occurring around $80 \%$ denervation and $\sim 10$ times increase above $96 \%$ denervation (Fig. $4 F$, blue). At high denervation, the aberrant $\mathrm{D}_{2}$ signal was as high as the phasic signal. The variability in the aberrant signals increased at high denervation (Fig. 4 E,F, blue shaded areas indicate standard error from $N=4$ independent trials).

In summary, a simple adaptive scheme based on negative feedback on postsynaptic signaling cascades may compensate reduced phasic signaling under moderate denervation. However, the resulting postsynaptic signal will deviate in several ways from that of the intact. The first deviation, overcompensation and undercompensation for $\mathrm{D}_{2}$ receptor-mediated dynamical signals, is a result of a mismatch between two fundamental time scales in the system. At high denervation, this shift in time scales is less of a concern because the combination of random fluctuations in the tonic DA level and adaptive postsynaptic pathways play the dominant role as a cause of error in the signal.

\section{Time scale mismatch renders $D_{2}$ receptor signals hypersensitive to DA uptake inhibitors}

Experimentally, PD is often investigated in rotation models in rodents where DA signals are manipulated by DA uptake inhibitors (Ungerstedt and Arbuthnott, 1970). In animal models of early PD, this experimental paradigm sometimes leads to counterintuitive behavior (Paquette et al., 2009). I therefore analyzed how blocking DA uptake would affect tonic and phasic DA signals in partial denervation.

The inhibitor was modeled by increasing $K_{\text {app}}$, the apparent Michaelis-Menten constant for DAT-mediated uptake. Note that changing $K_{\text {app }}$ has effects in both terminal and somatoden- dritic areas and, therefore, also alters firing rate of neurons in the model. Since $K_{\text {app }}$ is modeled as a constant, the results presented here apply to a steady-state concentration of a competitive uptake inhibitor. For easier comparison with in vivo data, I interpret the state of the uptake system as an equivalent intraperitoneal dose of cocaine administered 20 min earlier (Dreyer and Hounsgaard, 2013).

A full account of computational modeling of DAT inhibition in dorsal striatum and nucleus accumbens is given by Dreyer and Hounsgaard (2013). In brief, tonic DA levels are increased by steady-state DAT inhibition with only a slight change in phasic $D_{1}$ signals. Whereas the model predicts that activation of the $D_{2}$ receptor by tonic firing is unchanged by DAT inhibition, the downward phasic $\mathrm{D}_{2}$ receptor signal is quenched by saturation in a dose-dependent manner.

Similar effects were also observed when modeling uptake inhibition in the denervated striatum [Fig. $5 A$, effect of DAT inhibition in intact; dark red, $0 \mathrm{mg} / \mathrm{kg}$; bright red, $6 \mathrm{mg} / \mathrm{kg}$; orange, 15 $\mathrm{mg} / \mathrm{kg}$; Fig. $5 B$, effect of DAT inhibition in $50 \%$ denervation, $C$, summary of tonic (solid lines) and maximum and minimum (dashed lines) as a function of a simulated dose of cocaine for 3 degrees of denervation; blue, intact; green, 50\% denervated; red, $85 \%$ denervated]. DAT inhibition lead to a uniform increase in tonic DA, but the influence of denervation was minor (Fig. $5 A, B$, compare DA levels for tonic firing, $t<2 \mathrm{~s}$; summarized in Fig. $5 C$, blue, green, and red solid lines showing tonic DA nearly coinciding). The upward phasic amplitude was not changed by DAT inhibition but uniformly reduced by denervation (Fig. $5 A, B, t>$ $2 \mathrm{~s}, C$, top dashed lines) and thus did not influence model predic- 


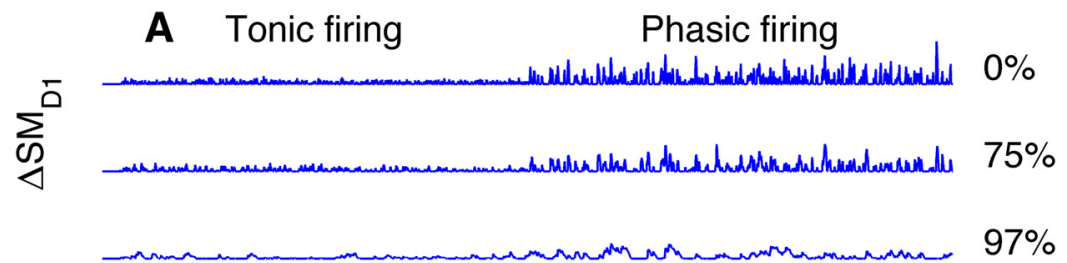

B
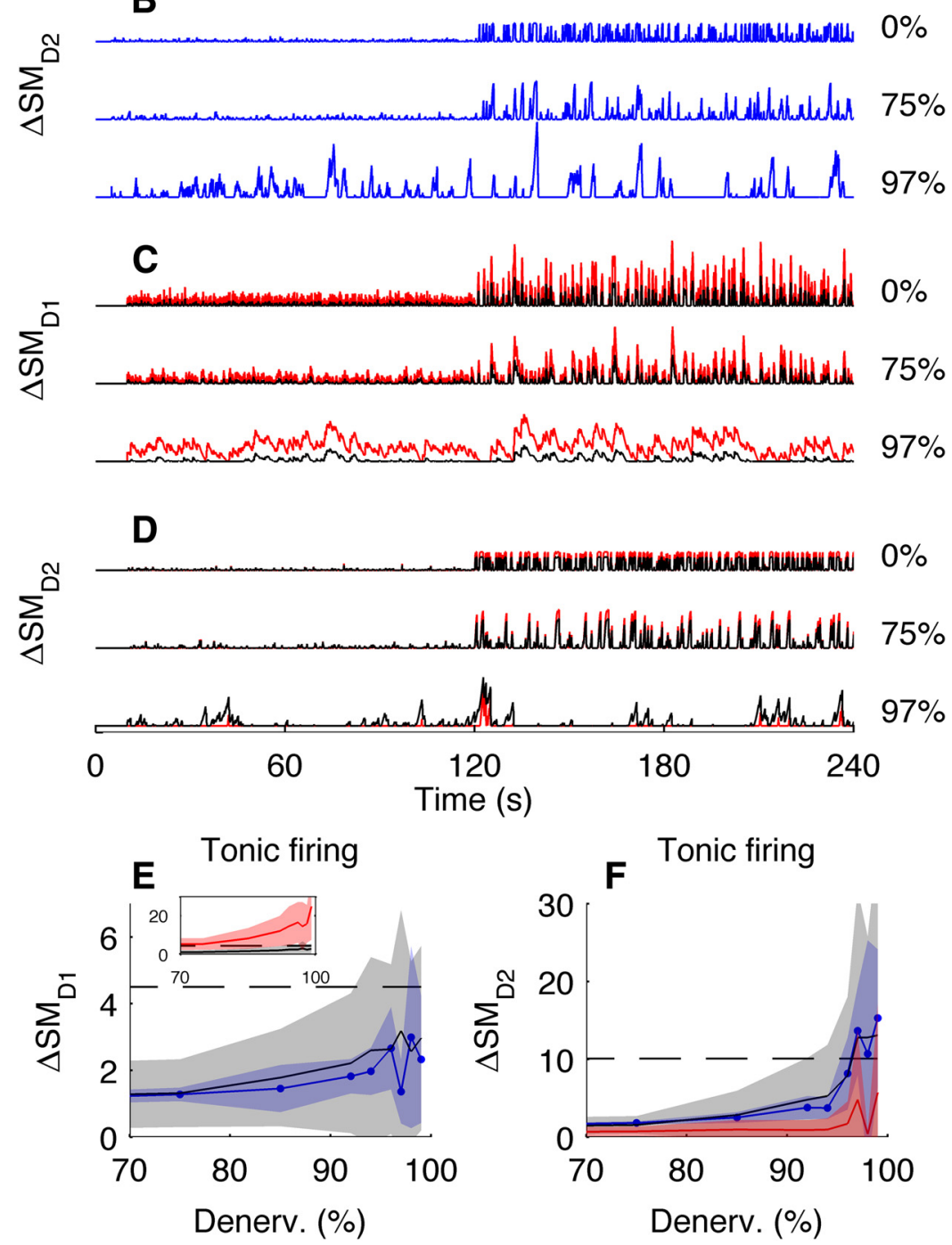

Figure 4. Postsynaptic compensation leads to false signals, partly alleviated by $\mathrm{L}$-dopa. $A, \Delta S \mathrm{M}_{\mathrm{D} 1}$, the rate of $S M$ production in $D_{1}$-regulated cascades, by tonic $(t<120 \mathrm{~s})$ and phasic $(t>120 \mathrm{~s})$ DA firing patterns at different degrees of denervation. $\boldsymbol{B}$, Same for $\Delta \mathrm{SM}_{\mathrm{D2}}$. C, Rate of SM production in $\mathrm{D}_{1}$-regulated cascades under simulation of $\mathrm{L}$-dopa therapy. Black, Adapted to L-dopa; red, before adaptation. $\boldsymbol{D}$, Same for $D_{2}$. $\boldsymbol{E}$, Relative increase in residual tonic $\Delta S M_{D 1}$ as function of denervation. Blue, Unmedicated; black, adapted to L-dopa; red, before adaptation to L-dopa (inset only). The black dashed line level of $\Delta S M_{D 1}$ by phasic firing in the intact. Shades indicate $\pm S D$ ( $n=4$ simulations). $\boldsymbol{F}$, Relative increase in residual $\Delta S M_{D 2}$ by tonic firing. Same colors as in $\boldsymbol{E}$. Dashed line indicates level of $\Delta \mathrm{SM}_{\mathrm{D} 2}$ by phasic firing in the intact.

tions regarding phasic signaling of $\mathrm{D}_{1}$ receptors. However, the reduction in downward phasic amplitude by denervation was strongly amplified by uptake inhibition (Fig. $5 C$, bottom dashed lines), and the predicted temporal signals on the $\mathrm{D}_{2}$ receptor were strongly affected by uptake inhibition (Fig. $5 G, H, t>2 \mathrm{~s}, I$, bottom dashed lines).

Focusing on the loss of phasic $\mathrm{D}_{2}$ signals, I calculated the predicted dose of intraperitoneal cocaine at which the phasic amplitude was reduced by $50 \%$. In the intact striatum, $50 \%$ re- duction occurred when $K_{\text {app }}=0.72 \mu \mathrm{M}$, which is equivalent to a dose of $10 \mathrm{mg} / \mathrm{kg}$, i.p., cocaine. However, at 50\% denervation, saturation occurred when $K_{\text {app }}=$ $0.40 \mu \mathrm{M}$, which is equivalent to a dose of $4.2 \mathrm{mg} / \mathrm{kg}$, i.p., cocaine, less than half the saturating dose in the intact case. The equivalent dose for saturation declined linearly with denervation until $80 \%$ denervation. When denervation was higher than $80 \%$, the phasic signal was so low that no further effect of uptake inhibition was observed. This analysis predicts a window with modest denervation in which $\mathrm{D}_{2}$ receptors are more likely to saturate by uptake inhibition. In rats with mild unilateral lesions, this $\mathrm{D}_{2}$ receptor this will lead to contraversive rotations when challenged with low doses of DA uptake inhibition (Robinson et al., 1994; Labandeira-Garcia et al., 1996; Paquette et al., 2009). Note that this dynamical effect requires a relatively low degree of denervation where DAT remains the major source for removing extracellular DA. In this regime, nonspecific uptake plays a vanishing role in the model. Consequently, MAO-B inhibitors, also used in PD therapy (Caslake et al., 2009), will not cause the above saturation of $\mathrm{D}_{2}$ like receptors.

\section{Macroscopic voids in innervation lead to regions with tonic low DA}

I have so far identified two mechanisms by which a pathological signal may arise. Both occur under conditions where DA tone is not reduced relative to the presymptomatic level. However, the micro-scale model only represents DA signaling if denervation occurs homogenously. However, such homogeneous denervation is unlikely in advanced idiopathic PD. Random loss of DA neurons will increase heterogeneity, and localized areas may eventually become completely void of DA innervation (Fig. 1C). Such regions may play a role in the pathological DA signal at advanced stages of PD (Kordower et al., 2013).

Given that the anatomical extent of DA axonal arbors may reach $1 \mathrm{~mm}$, I investigated how a DA void influences DA levels on a large spatial scale. Here the microscale model becomes intractable, and I therefore resort to a continuum model in simplified geometry where DA concentration is a function of a single spatial coordinate, $r$, indicating the distance from the center of the void (Eq. 3). DA release and DAT uptake is controlled by a continuous terminal density, $\rho(r)$ (Eqs. 4, 5), and a spherical DA void was implemented by setting $\rho(r)=0$ for $r \leq R_{\text {void }}$ and $\rho(r)=\rho_{0}$ for $r \leq R_{\text {void }}$ (Fig. $1 G$ and Eq. 2). Thus, innervated tissue with release and DAT-mediated uptake is located at $r>R_{\text {void }}$, whereas at $r \leq R_{\text {void, }}$, only first-order nonspecific uptake contributes to removal of DA. 
The dynamics and steady state of the system was determined numerically.

The simulation was initiated with a DA concentration equal to 0 everywhere. As the DA level was iterated, the concentration would increase at a time scale similar to the dynamical time scale $\tau$ $=K_{M} / V_{\max }$. Thus, in the innervated region far from the void, the DA level equilibrated fast. However, inside and near the edge, the time scale was reduced. The time for DA in the center to reach $50 \%$ of the steady-state level, $T_{1 / 2}$, increased linearly for large voids (Fig. 6A). When the void radius was $150 \mu \mathrm{m}, T_{1 / 2}$ was $10 \mathrm{~s}$; when the void radius was $500 \mu \mathrm{m}$, corresponding to the size of an axonal arbor (Matsuda et al., 2009), $T_{1 / 2}$ was nearly $1 \mathrm{~min}$. Thus, DA levels inside voids are essentially constant as phasic fluctuations in DA levels, which occur on a subsecond time scale, do not penetrate into the central regions of the void. Furthermore, the response to long-term changes in DA levels outside (both up and down) will be significantly delayed in large voids.

The steady-state DA concentration was low in the center and increased toward the edge (Fig. $6 B$, solid lines). The effect of $90 \%$ exterior denervation was relatively small on the interior DA level (Fig. $6 B$, dashed lines) and mainly affected DA levels at the boundary (Fig. 6B, inset). The central concentration of DA in the void center was dependent on void radius: for $R_{\text {void }}<100 \mu \mathrm{m}$, the DA level would remain above $30 \mathrm{~nm}$ in the center, whereas for $R_{\mathrm{void}}>$ $400 \mu \mathrm{m}$, the DA level was $<5 \mathrm{~nm}$ in the center (Fig. $6 C$, solid blue). DA levels in the center were only little affected by exterior denervation (Fig. 6C, dashed blue).

Finally, I asked how big a striatal volume would be affected by a critically low DA concentration $<10 \mathrm{~nm}$ as function of void size. Regions with critically low DA first appeared for voids larger than $300 \mu \mathrm{m}$. For larger voids, the affected volume grew fast (Fig. 6D).

Thus, in the models presented here, developed according to the biophysical and physiological constraints of DA signaling, constant low DA levels occur exclusively in fully depleted striatal areas (voids) of a size of larger than $100 \mu \mathrm{m}$. The occurrence of such voids seems likely at advanced stages of denervation given the anatomical structure of localized, overlapping DA axons (Fig. $1 A-D)$ and by certain experimental procedures such as intrastriatal injection of 6-OHDA (Labandeira-Garcia et al., 1996).

\section{L-Dopa reduces aberrant $D_{2}$ signaling and volume of critically low DA}

The gold-standard treatment of PD is administration of the dopamine precursor L-dopa. The therapeutic effect of L-dopa therapy is presumably due to increased intracellular stores of DA and thereby increased vesicular quantal release (Pothos et al., 1998; de la Fuente-Fernández et al., 2004). L-Dopa has beneficial effects in the beginning of the therapy, but eventually fluctuating response
Intact $50 \%$ denerv. B

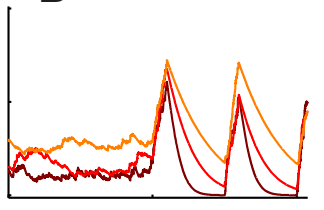

E
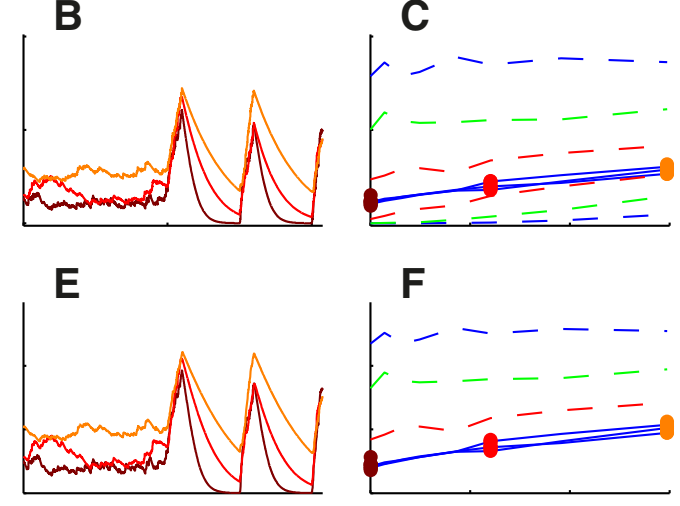

$\mathrm{H}$

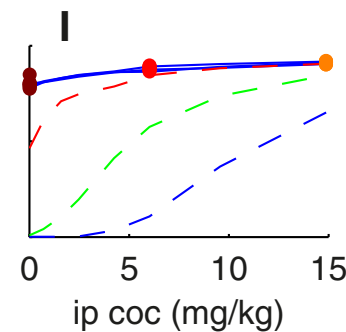

ime (s)

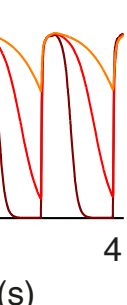

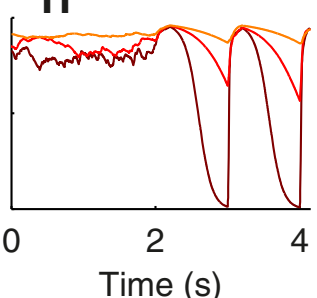

ition on

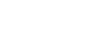

and phasic DA signals in intact $(\boldsymbol{A}, \boldsymbol{D}, \boldsymbol{G})$ and denervated striatum $(\boldsymbol{B}, \boldsymbol{E}, \boldsymbol{H})$. Columns 1 and 2: dark red, no uptake inhibition $(0 \mathrm{mg} / \mathrm{kg})$; bright red, equivalent of $6 \mathrm{mg} / \mathrm{kg}$, i.p., cocaine; orange, equivalent of degree of denervation. Dashed lines indicate peak $(\boldsymbol{C}, \boldsymbol{F}$, top $)$ and minimum $(\boldsymbol{C}, \boldsymbol{I}$, bottom) during phasic firing. Blue, Intact; green, degree of in on DA levels in the intact. $\boldsymbol{B}$, Same as $\boldsymbol{A}$, but with $50 \%$ denervation. $\boldsymbol{C}$, Summary of DA levels. $\boldsymbol{D}$, Effect of uptake inhibition on $D_{1}$ activation in the intact. $\boldsymbol{E}$, Same as $\boldsymbol{D}$, but with $50 \%$ denervation. $\boldsymbol{F}$, Summary of $D_{1}$ activation. $\boldsymbol{G}$, Effect of uptake inhibition on $D_{2}$ activation in the intact. $\boldsymbol{H}$, Same as $\boldsymbol{G}$, but with $50 \%$ denervation. $\boldsymbol{I}$, Summary of $D_{2}$ activation.

and dyskinesia develop. I asked whether the pathological signals described above are alleviated or further distorted when simulating the effect of L-dopa therapy. Here I modeled the effect of L-dopa administration as a threefold increase in DA vesicle contents assuming equal effects for somatodendritic and terminal release.

\section{L-Dopa increases DA levels and evokes response by DA autoreceptors}

To investigate the effect of L-dopa on DA levels and to determine the compensatory effects by DA autoreceptors, I first modeled the effect of L-dopa therapy using the micrometer-scale model (Fig. $1 E, F$, Fig. 2, black). I found L-dopa therapy was counteracted by autoreceptors at two levels: the strongest by somatodendritic autoreceptors in substantia nigra where tonic the firing rate was reduced from $4.1 \mathrm{~Hz}$ to $2.3 \mathrm{~Hz}$. In striatum, the vesicular release probability was reduced from $8 \%$ to $7 \%$.

Because of these adaptations, the effect of L-dopa administration on tonic DA levels was blunted. In the intact striatum, DA levels went from 50 to $70 \mathrm{~nm}$ with tonic firing of DA neurons (Fig. $2 A, B$, black). With a high degree of denervation, DA levels from tonic firing reached $100 \mathrm{nM}$ (Fig. $2 B$, inset, black). This was mediated by reduced somatodendritic autoreceptor feedback (tonic firing rate was $3.6 \mathrm{~Hz}$ at $99 \%$ denervation when simulating L-dopa therapy). The increase in DA levels during simulated L-dopa therapy was stronger with phasic signaling of DA neurons. Here time-averaged DA levels increased to $170 \mathrm{nM}$ compared with $70 \mathrm{~nm}$ in absence of L-dopa. 
A

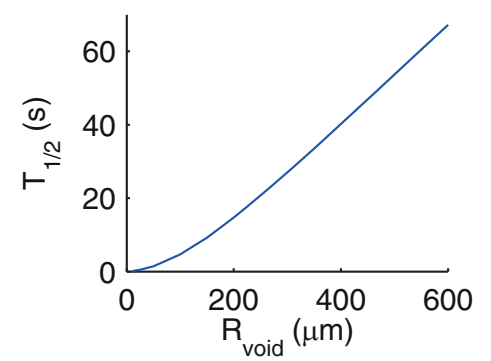

C

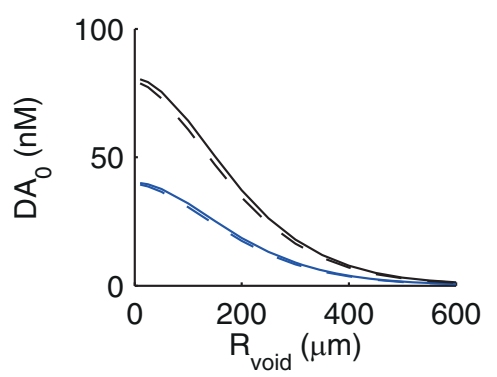

B

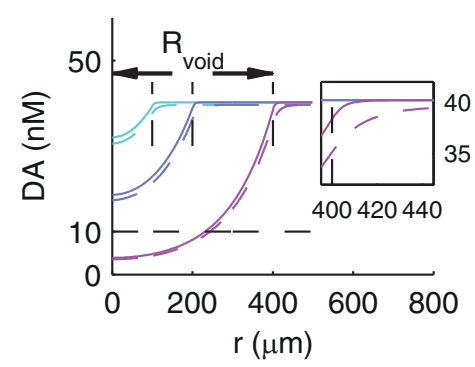

D

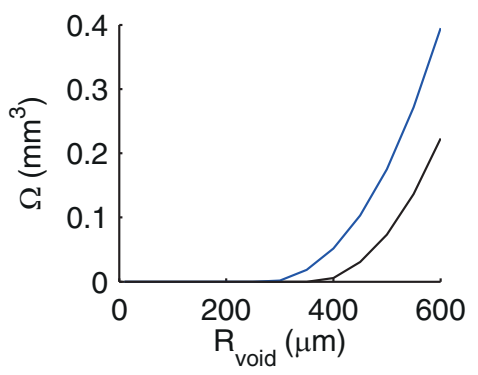

Figure 6. Effect of voids on steady-state DA levels. $A$, Time scale for reaching $50 \%$ of steady-state value as a function of void size. $B$, Steady-state DA concentration as a function of distance to the void center. Cyan, $R_{\text {void }}=100 \mu \mathrm{m}$; violet, $R_{\text {void }}=200 \mu \mathrm{m}$; pink, $R_{\text {void }}=400 \mu \mathrm{m}$. Inset, DA concentration around the void edge. The black dashed line indicates the $10 \mathrm{~nm}$ level. C, DA concentration in center concentration as a function of void size. Blue, Control; black, simulation of L-dopa therapy. D, Volume with a critically low DA level as a function of void size. Blue, Control; black, simulation of L-dopa therapy.

In the simulation, L-dopa therapy also increased the amplitude of DA transients from bursts. In the intact striatum, the increase in phasic amplitude was more than twofold, and with $75 \%$ denervation, the burst amplitude was approximately equal to the intact (Fig. 2A, compare black and blue at $t>6 \mathrm{~s}$ ). L-Dopa therapy essentially restored $D_{1}$ receptor sensitivity to burst firing (Fig. $2 C, D$ ) but did not improve phasic signaling for $\mathrm{D}_{2}$ receptors (Fig. 2E,F).

\section{L-Dopa transiently silences aberrant $\mathrm{D}_{2}$ signals but enhances aberrant $D_{1}$ signals}

I then asked whether L-dopa administration would affect translation of tonic and phasic firing patterns into production of SM molecules in $\mathrm{D}_{1}$ - and $\mathrm{D}_{2}$-regulated pathways. I first evaluated the immediate effect of $\mathrm{L}$-dopa therapy, i.e., when the effect is acting on postsynaptic signals compensated for denervation but not yet including the effect of L-dopa [Fig. $4 C$, red lines show $\mathrm{D}_{1^{-}}$ regulated postsynaptic response at $0 \%$ (top), $75 \%$ (middle), and 97\% (bottom) denervation]. An immediate increase in vesicle content gave a strong increase in postsynaptic $\mathrm{D}_{1}$ signaling from a tonic firing pattern. The increase was sixfold for denervation around $75 \%$ and $>20$-fold for denervation above $95 \%$ (Fig. $4 E$, inset, red).

The immediate response to L-dopa therapy was a strong reduction in residual $\mathrm{D}_{2}$ signals from the tonic firing pattern to levels even lower than intact (compare Fig. $4 D$, red traces, with Fig. $4 B$, blue traces, for $t<120 \mathrm{~s}$ ).

However, the adaptive postsynaptic signals of the present model also act to compensate the effect of L-dopa. For $\mathrm{D}_{1}$ receptor-mediated signals, L-dopa lead to reduction of postsynaptic signaling units as expressed in $N_{\mathrm{D} 1}$. The reduction was present at all stages of denervation (Fig. $3 D$, black). In the $\mathrm{D}_{2}$ system, the effect of L-dopa on $N_{\mathrm{D} 2}$ was much less (Fig. $3 E$, black, com- pare with blue). With ongoing compensation, the high $\mathrm{D}_{1}$ signal was reduced and ended up being similar to the untreated signal [compare Fig. 4, C (black, fully adapted L-dopa), $A$; compare also Fig. $4, E$ (black line, adapted L-dopa), blue line (untreated)]. In $\mathrm{D}_{2}$-regulated cascades, adaptation to the effect of $\mathrm{L}$-dopa lead to reappearance of aberrant $\mathrm{D}_{2}$ signals [compare Fig. 4, $D$ (black, fully adapted L-dopa), $B$; compare also Fig. $4, F$ (black line, adapted L-dopa), blue line (untreated)]. However, the variability in the fully adapted postsynaptic signals was generally higher under L-dopa, an effect particularly strong in the $\mathrm{D}_{1}$-regulated pathways (Fig. 4E, compare black and blue shades).

Thus, according to the theoretical analysis, L-dopa therapy provides a temporal benefit for persistent aberrant signals in the passive stabilized phase. The effect, however, is only beneficial as long as adaptation to overload in $\mathrm{D}_{1}$ signals is fast while at the same time adaptation to lower-than-normal $\mathrm{D}_{2}$ signals is slow.

\section{L-Dopa increases penetration of DA to voids}

A prediction of the present analysis is that voids in DA innervation occurring late in disease progression will result in low DA levels. I therefore also investigated the effect of $\mathrm{L}$-dopa therapy in DA levels in the presence of voids. Compensation of L-dopa therapy by autoreceptors was included implicitly by reducing release probability from $8 \%$ to $7 \%$ and by reducing the tonic firing rate from $4 \mathrm{~Hz}$ to $3 \mathrm{~Hz}$, reflecting results from the micro-scale model. With these adjustments, simulation L-dopa therapy gave an approximately twofold increase in extracellular DA concentration in innervated areas. Thereby DA levels in the center of the voids also increased (Fig. 6C, black), and, in particular, the volume affected by critically low DA was completely ablated for small voids and reduced for large voids (Fig. $6 D$, black).

\section{Effect of DA corelease from serotonergic terminals}

A number of studies have suggested that high doses of L-dopa may also cause DA corelease from striatal serotonergic terminals and have shown that this may play a role in dyskinesia (Carta et al., 2008). Here I will provide a brief estimate of the impact of DA corelease from serotonin terminals and ask under which conditions this may be a relevant contribution.

The density of serotonin terminals in striatum is 0.0026 $\mu \mathrm{m}^{-3}$, around 2\% of intact DA innervation (Doucet et al., 1986; Soghomonian et al., 1987), and the spontaneous firing rate of serotonergic neurons is $\sim 1 \mathrm{~Hz}$ (Aghajanian et al., 1978). With these parameters, the contribution of DA corelease is vanishing in the presence of DA innervation. Taking the extreme case, with $1 \%$ remaining DA innervation, nominal DA release alone generates $60 \mathrm{~nm}$ under L-dopa (using same parameters as above). If we include additional serotonergic mediated DA release (300 DA molecules per vesicle, $\sim 10 \%$ of typical vesicle contents), the total DA level becomes $64 \mathrm{~nm}$. Thus, with homogeneous denervation, the extra contribution from serotonergic corelease is $<10 \%$. If 
the firing rate of serotonergic neurons is doubled, total DA levels increase by merely $7 \%$.

However, in a fully depleted region, the situation is different: in this case, DA corelease will be balanced only by weak nonspecific uptake, and the steady-state DA level will be $16 \mathrm{~nm}$, similar to the $\mathrm{EC}_{50}$ for high-affinity receptors, and may increase by $100 \%$ if the serotonin firing rate is doubled. Thus, provided that L-dopa administration adds a few hundred DA molecules to serotonin vesicles, these may contribute significantly to extracellular DA and, therefore, add to the therapeutic effect of L-dopa in fully depleted regions.

\section{Discussion}

Here I used a recently developed biophysical model of DA signaling and a novel continuum scale model to conduct a theoretical analysis of striatal DA signals at different stages of denervation. The aim was to present a theoretical account for symptoms of PD consistent with clinical observations; animal studies; and basic biophysics, anatomy, and physiology of DA neurons.

The accuracy and degree of detail accessible in this study are obviously limited by the available experimental parameters. While physiological parameters describing DA release and uptake are relatively well known, much less is known about the dynamical response of different members of the $D_{1}$-like $\left(D_{1}\right.$ and $\left.D_{5}\right)$ and $D_{2}$-like $\left(D_{2}, D_{3}\right.$, and $\left.D_{4}\right)$ families and their response to subsecond DA signals, in particular. Therefore, I only characterize postsynaptic receptors by their class and determine their contribution to development of striatal malfunction solely on the basis of high or low affinity.

The picture that emerges is that denervation may distort the postsynaptic readout of the DA signal in three ways. If the DA innervation remains coherent (Fig. 1B), concurrent loss of DA release and uptake leads to passive stabilization of DA levels (Bergstrom and Garris, 2003). Here the DA level becomes increasingly locked at the tonic level, whereas transient signals in cell firing are reduced. The stabilizing effect is remarkably strong: within the arborization of just a single remaining DA axon, the local DA tone remains, by a wide margin, sufficient to saturate high-affinity DA receptors. Thus, in partially denervated regions, the perturbation of the DA signal is, in some respects, opposite of the classical interpretation of PD (Lewis et al., 2003). In particular, the predicted average $\mathrm{D}_{2}$ receptor activation is higher than the intact under conditions where phasic firing patterns dominate. However, despite high DA levels, aberrant signals consistent with classical PD arise.

The first sign of malfunction is a mismatch between time scales of DA cell firing and the dynamics of striatal extracellular DA. With time scale mismatch, there will be a distortion of the postsynaptic readout from small and large phasic events, in particular, in the $\mathrm{D}_{2}$-regulated pathway. The current analysis predicts that under this condition, $\mathrm{D}_{2}$ receptors saturate easily by low doses of DA uptake inhibition, implying increased sensitivity to locomotor stimulants like cocaine (Fig. 5). Therefore, time scale mismatch may explain contraversive rotations in rat models of early PD (Robinson et al., 1994; LabandeiraGarcia et al., 1996; Paquette et al., 2009). If this hypothesis is correct, hypersensitivity toward DA uptake inhibitors may serve as a test for premotor PD.

With increasing denervation, a second malfunction takes over. Now, a low signal-to-noise ratio between tonic and phasic signals causes an abnormal persistent $\mathrm{D}_{2}$-mediated signal (Fig. $4 B, F)$. It may seem paradoxical that this signal arises while activation of the receptor itself is high and that $\mathrm{L}$-dopa alleviates the signal. However, the lack of phasic DA signals force postsynaptic pathways to upregulate until small random fluctuations in the tonic DA level are amplified. Interestingly, the present theory does not predict any particular rotational pattern in animal models with unilateral lesions affected by this pathological signal under amphetamine challenge. Rather, the theory predicts that such animals respond to $\mathrm{D}_{1} / \mathrm{D}_{2}$ agonists by contraversive rotations and that the supersensitive $\mathrm{D}_{2}$ pathway will be hypersensitive to $\mathrm{D}_{2}$ antagonists like haloperidol.

However, as denervation proceeds even further, spatial coherence of the remaining innervation is unlikely, and voids may emerge (Fig. 1C). This generates the third, and possibly most severe, mechanism for aberrant signals occurring in advanced PD. The analysis showed that DA levels inside voids were low and decreased as a function of void size. When the void radius exceeded $300 \mu \mathrm{m}$, the DA concentration in the center was $<10 \mathrm{nM}$, presumably low enough to induce another aberrant signal on high-affinity DA receptors. Therefore, DA voids perturb DA signaling in the way typically expected in PD and will induce classical ipsiversive rotations in unilateral animal models when challenged with high-dose amphetamine (Ungerstedt and Arbuthnott, 1970; Labandeira-Garcia et al., 1996).

In patients with advanced idiopathic $\mathrm{PD}$, the spectrum of symptoms probably reflects a mixture of areas with partial denervation and voids. According to the present analysis, administration of the DA precursor L-dopa has beneficial effects for some of these: in passive stabilized regions, it transiently alleviates the effect of random fluctuations and also reduces the volume affected by critically low DA levels in voids. However, according to the analysis presented here, the potential success of L-dopa therapy is limited by several factors. Persistent aberrant signals in the passive stabilized phase are only alleviated as long as $\mathrm{D}_{2}$ compensation is slow. Once full compensation is reached, the required dose needs to be increased to regain the effect. It is, therefore, tempting to suggest that a transient reduction in medication may reverse adaptation ("drug holiday"). However, the hypothesis of adaptive postsynaptic pathways suggests that a sudden reduction of DA tone in the $\mathrm{D}_{2}$ pathway may lead to an extreme response in $\mathrm{SM}$ production. If DA tone suddenly drops, there may be a catastrophic surplus of permanently unblocked adenylyl cyclase units. Reversal of this situation can potentially be slow since it requires either synthesis of more $\mathrm{D}_{2}$ receptors or removal of adenylyl cyclase. Thus the present analysis is consistent with the clinical effects and pitfalls of drug holidays in PD (Weiner et al., 1980; Toru et al., 1981).

The analysis presented here suggests that with L-dopa therapy, adaptation in the $\mathrm{D}_{1}$-regulated pathway is desirable. However the model also predicts that postsynaptic compensation is increasingly prone to error at high denervation where feedback from the postsynaptic accumulation of SM molecules becomes irregular and dominated by few large events. The problem is exaggerated because at high denervation, where adaption is difficult, the initial $D_{1}$ overshoot by L-dopa is very high (Fig. $4 C$, red, $E$, inset, red). Therefore, the present analysis is consistent with the idea that $\mathrm{L}$-dopa therapy eventually causes false signaling in the $\mathrm{D}_{1}$ pathway, possibly leading to L-dopa-induced dyskinesia (Gerfen, 2000). The model points toward two mechanisms that can cause abnormally high activation of the $\mathrm{D}_{1}$ system. As observed above, changes in tonic $\mathrm{DA}$ levels will require increasing compensation. Such changes can be induced by pharmacodynamics of L-dopa medication and by variations in serotonergic cell activity (assuming DA corelease from serotonergic neurons is sufficiently high). Second, the residual activation of $\mathrm{D}_{1}$-regulated pathways will also contain a large random compo- 
nent that is enhanced by L-dopa (Fig. $4 E$, compare black shade, L-dopa, and blue shade, control). The increased variability has a double effect. First, changes in $\mathrm{D}_{1}$ signals mediated by variations in tonic DA will have an increasingly long time to compensate. However, long-lived random fluctuations it may in itself create false signals even under ideal steady state conditions (Fig. $4 E$, black shade exceeds intact phasic signals, black dashed).

These observations are in agreement with studies showing that more precise delivery of L-dopa and control of serotonergic neurons retards the onset of dyskinesia (Obeso et al., 1994; Carta et al., 2008). However, according to the present model, the root cause of dyskinesia is not fluctuations in DA levels themselves, but rather the lack of subsecond temporal DA signals. With the assumption of negative feedback regulating postsynaptic pathways, strategies aimed at maintaining constant DA levels will only postpone dyskinesia. In the long run, the adaptation will catch up, and dyskinesia will return. In the present analysis I used L-dopa as a typical medication for PD. However DA agonists acting on different combinations of D1, D2, and D3 receptors are also used, often in the early stage of the disease where some DA innervation may be remaining. Precise predictions of the combined effect of medication and remaining DA are not within scope of the present model. However, if agonist concentrations are essentially tonic, their effects may eventually be reduced by compensation (in Eqs. 9 and 10, tonic D1 and D2 occupancies are subtracted). Therefore, according to this model, DA agonists may face the same challenge as L-dopa: that their effect can be reduced by adaptive mechanisms.

In summary, this theoretical analysis of the biophysics of DA signaling at different stages of denervation paints a more faceted picture of $\mathrm{PD}$ than usually proposed. Low tonic $\mathrm{DA}$ is only one cause of pathological signaling and the one that occurs in advanced stages of PD. I identified two additional mechanisms by which DA denervation leads to deficits. These other mechanisms appear earlier in disease progression where tonic DA levels and $\mathrm{D}_{2}$ receptor occupancy appear normal. One is linked to mismatch between time scales, and the other results in the combination of reduced signal-to-noise ratio and supersensitive postsynaptic signals and is alleviated by L-dopa.

\section{References}

Aghajanian GK, Wang RY, Baraban J (1978) Serotonergic and nonserotonergic neurons of the dorsal raphe: reciprocal changes in firing induced by peripheral nerve stimulation. Brain Res 153:169-175. CrossRef Medline

Albin RL, Young AB, Penney JB (1989) The functional anatomy of basal ganglia disorders. Trends Neurosci 12:366-375. CrossRef Medline

Barton AC, Sibley DR (1990) Agonist-induced desensitization of D1dopamine receptors linked to adenylyl cyclase activity in cultured NS20Y neuroblastoma cells. Mol Pharmacol 38:531-541. Medline

Beaulieu JM, Gainetdinov RR (2011) The physiology, signaling, and pharmacology of dopamine receptors. Pharmacol Rev 63:182-217. CrossRef Medline

Bergstrom BP, Garris PA (2003) “Passive stabilization" of striatal extracellular dopamine across the lesion spectrum encompassing the presymptomatic phase of Parkinson's disease: a voltammetric study in the 6-OHDA-lesioned rat. J Neurochem 87:1224-1236. CrossRef Medline

Bonci A, Hopf FW (2005) The dopamine D2 receptor: new surprises from an old friend. Neuron 47:335-338. CrossRef Medline

Brooks DJ, Ibanez V, Sawle GV, Playford ED, Quinn N, Mathias CJ, Lees AJ, Marsden CD, Bannister R, Frackowiak RS (1992) Striatal D2 receptor status in patients with Parkinson's disease, striatonigral degeneration, and progressive supranuclear palsy, measured with 11C-raclopride and positron emission tomography. Ann Neurol 31:184-192. CrossRef Medline

Budygin EA, John CE, Mateo Y, Jones SR (2002) Lack of cocaine effect on dopamine clearance in the core and shell of the nucleus accumbens of dopamine transporter knock-out mice. J Neurosci 22:RC222(1-4). Medline

Cai G, Wang HY, Friedman E (2002) Increased dopamine receptor signaling and dopamine receptor- $\mathrm{G}$ protein coupling in denervated striatum. J Pharmacol Exp Ther 302:1105-1112. CrossRef Medline

Carta M, Carlsson T, Munoz A, Kirik D, Bjorklund A (2008) Involvement of the serotonin system in L-dopa-induced dyskinesias. Parkinsonism Relat Disord 14 [Suppl 2]:S154-S158. CrossRef Medline

Caslake R, Macleod A, Ives N, Stowe R, Counsell C (2009) Monoamine oxidase B inhibitors versus other dopaminergic agents in early Parkinson's disease. Cochrane Database Syst Rev CD006661. CrossRef Medline

CastañedaE, Whishaw IQ, Robinson TE (1990) Changes in striatal dopamine neurotransmission assessed with microdialysis following recovery from a bilateral 6-OHDA lesion: variation as a function of lesion size. J Neurosci 10:1847-1854. Medline

Cragg SJ, Nicholson C, Kume-Kick J, Tao L, Rice ME (2001) Dopaminemediated volume transmission in midbrain is regulated by distinct extracellular geometry and uptake. J Neurophysiol 85:1761-1771. Medline

Dauer W, Przedborski S (2003) Parkinson's disease: mechanisms and models. Neuron 39:889-909. CrossRef Medline

de la Fuente-Fernández R, Schulzer M, Mak E, Calne DB, Stoessl AJ (2004) Presynaptic mechanisms of motor fluctuations in Parkinson's disease: a probabilistic model. Brain 127:888-899. CrossRef Medline

Doucet G, Descarries L, Garcia S (1986) Quantification of the dopamine innervation in adult rat neostriatum. Neuroscience 19:427-445. CrossRef Medline

Dreyer JK, Hounsgaard J (2013) Mathematical model of dopamine autoreceptors and uptake inhibitors and their influence on tonic and phasic dopamine signaling. J Neurophysiol 109:171-182. CrossRef Medline

Dreyer JK, Herrik KF, Berg RW, Hounsgaard JD (2010) Influence of phasic and tonic dopamine release on receptor activation. J Neurosci 30:1427314283. CrossRef Medline

Gerfen CR (2000) Molecular effects of dopamine on striatal-projection pathways. Trends Neurosci 23:S64-70. CrossRef Medline

Gerfen CR (2003) D1 dopamine receptor supersensitivity in the dopaminedepleted striatum animal model of Parkinson's disease. Neuroscientist 9:455-462. CrossRef Medline

Grace AA, Bunney BS (1984a) The control of firing pattern in nigral dopamine neurons: single spike firing. J Neurosci 4:2866-2876. Medline

Grace AA, Bunney BS (1984b) The control of firing pattern in nigral dopamine neurons: burst firing. J Neurosci 4:2877-2890. Medline

Hobson DE, Pourcher E, Martin WR (1999) Ropinirole and pramipexole, the new agonists. Can J Neurol Sci 26 [Suppl 2]:S27-S33. Medline

Hornykiewicz O (2001) Chemical neuroanatomy of the basal ganglianormal and in Parkinson's disease. J Chem Neuroanat 22:3-12. CrossRef Medline

Howard CD, Keefe KA, Garris PA, Daberkow DP (2011) Methamphetamine neurotoxicity decreases phasic, but not tonic, dopaminergic signaling in the rat striatum. J Neurochem 118:668-676. CrossRef Medline

Howard CD, Daberkow DP, Ramsson ES, Keefe KA, Garris PA (2013) Methamphetamine-induced neurotoxicity disrupts naturally occurring phasic dopamine signaling. Eur J Neurosci 38:2078-2088. CrossRef Medline

Kish SJ, Shannak K, Hornykiewicz O (1988) Uneven pattern of dopamine loss in the striatum of patients with idiopathic Parkinsons disease-pathophysiologic and clinical implications. N Engl J Med 318:876-880. CrossRef Medline

Knudsen GM, Karlsborg M, Thomsen G, Krabbe K, Regeur L, Nygaard T, Videbaek C, Werdelin L (2004) Imaging of dopamine transporters and D2 receptors in patients with Parkinson's disease and multiple system atrophy. Eur J Nucl Med Mol Imaging 31:1631-1638. CrossRef Medline

Kordower JH, Olanow CW, Dodiya HB, Chu Y, Beach TG, Adler CH, Halliday GM, Bartus RT (2013) Disease duration and the integrity of the nigrostriatal system in Parkinson's disease. Brain 136:2419-2431. CrossRef Medline

Labandeira-Garcia JL, Rozas G, Lopez-MartinE, Liste I, Guerra MJ (1996) Time course of striatal changes induced by 6-hydroxydopamine lesion of the nigrostriatal pathway, as studied by combined evaluation of rotational behaviour and striatal Fos expression. Exp Brain Res 108:69-84. Medline Lewis SJ, Caldwell MA, Barker RA (2003) Modern therapeutic approaches in Parkinson's disease. Expert Rev Mol Med 5:1-20. Medline

Lindgren HS, Dunnett SB (2012) Cognitive dysfunction and depression in 
Parkinson's disease: what can be learned from rodent models? Eur J Neurosci 35:1894-1907. CrossRef Medline

Matsuda W, Furuta T, Nakamura KC, Hioki H, Fujiyama F, Arai R, Kaneko T (2009) Single nigrostriatal dopaminergic neurons form widely spread and highly dense axonal arborizations in the neostriatum. J Neurosci 29:444-453. CrossRef Medline

May T (1992) Striatal dopamine-D1-like receptors have higher affinity for dopamine in ethanol-treated rats. Eur J Pharmacol 215:313-316. CrossRef Medline

Obeso JA, Grandas F, Herrero MT, Horowski R (1994) The role of pulsatile versus continuous dopamine receptor stimulation for functional recovery in Parkinson's disease. Eur J Neurosci 6:889-897. CrossRef Medline

Paquette MA, Marsh ST, Hutchings JE, CastañedaE (2009) Amphetamineevoked rotation requires newly synthesized dopamine at 14 days but not 1 day after intranigral 6-OHDA and is consistently dissociated from sensorimotor behavior. Behav Brain Res 200:197-207. CrossRef Medline

Porter-Stransky KA, Seiler JL, Day JJ, Aragona BJ (2013) Development of behavioral preferences for the optimal choice following unexpected reward omission is mediated by a reduction of D2-like receptor tone in the nucleus accumbens. Eur J Neurosci 38:2572-2588. CrossRef Medline

Pothos EN, Davila V, Sulzer D (1998) Presynaptic recording of quanta from midbrain dopamine neurons and modulation of the quantal size. J Neurosci 18:4106-4118. Medline

Prieto GA, Perez-Burgos A, Fiordelisio T, Salgado H, Galarraga E, DruckerColin R, Bargas J (2009) Dopamine D(2)-class receptor supersensitivity as reflected in $\mathrm{Ca} 2+$ current modulation in neostriatal neurons. Neuroscience 164:345-350. CrossRef Medline

Rangel-Barajas C, Silva I, Lopéz-SantiagoLM, Aceves J, Erlij D, FloránB (2011) L-DOPA-induced dyskinesia in hemiparkinsonian rats is associated with up-regulation of adenylyl cyclase type V/VI and increased GABA release in the substantia nigra reticulata. Neurobiol Dis 41:51-61. CrossRef Medline

Reed MC, Best JA, Nijhout HF (2009) Passive and active stabilization of dopamine in the striatum. Biosci Hypotheses 2:240-244. CrossRef
Robinson TE, Noordhoorn M, Chan EM, Mocsary Z, Camp DM, Whishaw IQ (1994) Relationship between asymmetries in striatal dopamine release and the direction of amphetamine-induced rotation during the first week following a unilateral 6-OHDA lesion of the substantia nigra. Synapse 17:16-25. CrossRef Medline

Sandberg SG, Phillips PEM (2009) Phasic dopaminergic signaling: implications for Parkinson's disease. In: Cortico-subcortical dynamics in Parkinson's disease (Tseng K-Y, ed), pp 37-54. New York: Humana.

Schultz W (1998) Predictive reward signal of dopamine neurons. J Neurophysiol 80:1-27. Medline

Soghomonian JJ, Doucet G, Descarries L (1987) Serotonin innervation in adult rat neostriatum. I. Quantified regional distribution. Brain Res 425: 85-100. CrossRef Medline

StrömbergI, Kehr J, Andbjer B, Fuxe K (2000) Fetal ventral mesencephalic grafts functionally reduce the dopamine D2 receptor supersensitivity in partially dopamine reinnervated host striatum. Exp Neurol 164:154-165. CrossRef Medline

Sun W, Sugiyama K, Fang X, Yamaguchi H, Akamine S, Magata Y, Namba H (2010) Different striatal D2-like receptor function in an early stage after unilateral striatal lesion and medial forebrain bundle lesion in rats. Brain Res 1317:227-235. CrossRef Medline

Syková E, Nicholson C (2008) Diffusion in brain extracellular space. Physiol Rev 88:1277-1340. CrossRef Medline

Toru M, Matsuda O, Makiguchi K, Sugano K (1981) Neuroleptic malignant syndrome-like state following a withdrawal of anti-Parkinsonian drugs. J Nerv Ment Dis 169:324-327. CrossRef Medline

Ungerstedt U, Arbuthnott GW (1970) Quantitative recording of rotational behavior in rats after 6-hydroxy-dopamine lesions of the nigrostriatal dopamine system. Brain Res 24:485-493. CrossRef Medline

Weiner WJ, Koller WC, Perlik S, Nausieda PA, Klawans HL (1980) Drug holiday and management of Parkinson disease. Neurology 30:1257-1261. CrossRef Medline 